Conclusions These preliminary results show that children to mothers with bipolar disorder, with or without intrauterine exposure to lithium, had a normal to high IQ at preschool age. 5 more children have been tested, results to be analyzed, and additional children will be recruited.

\section{PRENATAL EXPOSURE TO HYDROXYLATED POLYCHLORINATED BIPHENYLS IS ASSOCIATED WITH THE QUALITY OF THE MOTOR REPERTOIRE IN THREE-MONTH- OLD INFANTS}

doi:10.1136/archdischild-2012-302724.0637

SA Berghuis, SD Soechitram, MM Hitzert, PJJ Sauer, AF Bos. University of Groningen, Groningen, The Netherlands

Background and Aim Polychlorinated biphenyls (PCBs) are ubiquitous environmental toxins, potentially toxic to the developing brain. Hydroxylated PCBs (OH-PCBs) are suggested to be even more toxic because of hydroxylation by the fetus and active transplacental transport of OH-PCBs. Still, little is known about their short-term health effects in humans. We aimed to determine whether prenatal exposure to OH-PCBs is associated with the neurological condition in three-month-old infants, assessed by the quality of the motor repertoire.

Methods In a Dutch observational cohort study, 97 mother-infant pairs participated. Cord blood samples were analyzed for PCB and $\mathrm{OH}-\mathrm{PCB}$ concentrations. The quality of the motor repertoire was evaluated at 3 months from video-recordings. We determined the quality of General Movements (GMs) and calculated a Motor Optimality Score (MOS) ranging from 5 to 28 (low to high optimality). We explored correlations between $\mathrm{PCB} / \mathrm{OH}-\mathrm{PCB}$ levels and MOS using Spearman's Rank correlation. Next, we tested whether PCB/ $\mathrm{OH}-\mathrm{PCB}$ levels differed between infants with 'low' $(<26)$ and 'high' MOS $(\geq 26)$.

Results We found no association between $\mathrm{PCB} / \mathrm{OH}-\mathrm{PCB}$ levels and the quality of GMs. Associations existed between several PCB/OHPCB levels and MOS, including detailed aspects of the motor repertoire. High 4-OH-PCB-107 levels were associated with a low MOS $(P=0.013)$. High PCB-187 levels were associated with reduced midline arm and leg movements ( $P=0.047$ and $P=0.043$, respectively).

Conclusion Prenatal exposure to higher 4-OH-PCB-107 levels was associated with a non-optimal quality of the motor repertoire in three-month-old infants. This negative effect may be mediated by reduced thyroid hormone concentrations in the brain.

\section{IMPACT OF WATCHING TV/PLAYING GAMES ON MENTAL HEALTH AND LEARNING OF UAE CHILDREN}

doi:10.1136/archdischild-2012-302724.0638

S Yousef. Faculty of Medical Sciences, Al Ain, United Arab Emirates

Background United Arab Emirates (UAE) is a rapidly changing society, and little is known about the children's free-time activities and their interference with the development and behavior. The recommendations of the American Academy of Pediatrics (AAP) state that children older than 2 years should watch quality television (TV) programs not more than 2 hours per day; and those younger than 2 years should avoid any TV viewing. Previous studies linked early TV viewing with later developmental and behavioral problems.

Aims Esstimate average amount of daily time of TV/video games viewing in UAE children; and sociodemographic, behavior and other variables associated with TV/video games viewing.

Methods In a case control study, 211 school children (68\% males, mean age 8.7 years) from United Arab Emirates were investigated. The children with developmental and behavioral disorders $(n=98)$ were compared with children without any developmental and behavioral disorders $(n=113)$ in regard to the time of watching TV/ video games per day.

Results children who watched TV/playing games over 2 hours/ day had significantly ADHD and higher total CBCL scored than the children who watched TV/playing games less than 2 hours/day. The two groups also differed on the following CBCL subscales: withdrawn, attention, aggressive and delinquent behavior. In terms of learning abilities and IO levels were did not differed from the children who watched TV/playing games less than 2 hours/day.

Conclusions $1 / 3$ of children in UAE viewed TV/video games for more than the recommended 2 hours per day which found to be associated more with behavioral problems.

\section{HIGH INCIDENCE OF CHILDHOOD TYPE 1 DIABETES IN OATAR BETWEEN 2006 AND 2011}

doi:10.1136/archdischild-2012-302724.0639

A Soliman, M Alali, A Elawwa, N Elsayed. Pediatrics, Hamad Medical Center, Doha, Oatar

The overall age-adjusted incidence of type 1 diabetes varied from $0.1 / 100,000$ per year in China and Venezuela to $36.8 / 100,000$ per year in Sardinia and 36.5/100,000 per year in Finland. This represents a 350 -fold variation in the incidence among the 100 populations worldwide.

Objective The aim of this study was to determine the incidence of type 1 diabetes among children aged 0-14 years in Qatar.

Research design and methods This was a prospective cohort study of the incidence of childhood type 1 diabetes in children aged 0-14 years who were diagnosed with type 1 diabetes from 2006 to 2011 on Qatar. Identified case subjects during this time period were ascertained from several sources and verified using the capturerecapture technique. Data were obtained from the only pediatric diabetes treatment center, Hamad Medical Center (HMC) for children living in Qatar

Results Over the study period, 385 children aged 0-14 years in Qatar were diagnosed with type 1 diabetes. The incidence of type 1 diabetes in this population over the period 2006-2011 inclusive was 23.11 with a $95 \%$ CI of 31.82-40.03.

\section{Abstract 639 Table 1}

\begin{tabular}{lc}
\hline Year & Incidence/100000 \\
\hline 2006 & 18.63 \\
2007 & 30.64 \\
2008 & 21.64 \\
2009 & 22.91 \\
2010 & 21.22 \\
2011 & 23.64 \\
\hline
\end{tabular}

Conclusions Qatar has a relatively high incidence of type 1 diabetes compared to incidences reported worldwide. The incidence increased over the 16-year study period.

\section{PREVALENCE OF GESTATIONAL DIABETES AND ASSOCIATED MATERNAL AND NEONATAL COMPLICATIONS IN A FAST DEVELOPING COMMUNITY: GLOBAL COMPARISONS}

doi:10.1136/archdischild-2012-302724.0640

A Bener. Weill Cornell Medical College \& Hamad Medical Corporation, Doha, Oatar

Objective To determine the prevalence of Gestational diabetes, compare the maternal-neonatal complications among women with GDM and non-GDM pregnant women and investigate the risk factors associated with GDM. 